\title{
Homology modeling and docking studies on oxidosqualene cyclases associated with primary and secondary metabolism of Centella asiatica
}

\author{
Vadlapudi Kumar*, Chethan S Kumar, Gajula Hari, Nayana K Venugopal, Poornima D Vijendra \\ and Giridhara Basappa B
}

\begin{abstract}
Centella asiatica is a well-known medicinal plant, produces large amount of triterpenoid saponins, collectively known as centelloids, with a wide-spectrum of pharmacological applications. Various strategies have been developed for the production of plant secondary metabolites in cell and tissue cultures; one of these is modular metabolic engineering, in which one of the competitive metabolic pathways is selectively suppressed to channelize precursor molecules for the production of desired molecules by another route. In plants the precursor 2,3oxidosqualene is shared in between two competitive pathways involved with two isoforms of oxidosqualene cyclases. One is primary metabolic route for the synthesis of phytosterol like cycloartenol by cycloartenol synthase; another is secondary metabolic route for the synthesis of triterpenoid like $\beta$-amyrin by $\beta$-amyrin synthase. The present work is envisaged to evaluate specific negative modulators for cycloartenol synthase, to channelize the precursor molecule for the production of triterpenoids. As there are no experimentally determined structures for these enzymes reported in the literature, we have modeled the protein structures and were docked with a panel of ligands. Of the various modulators tested, ketoconazole has been evaluated as the negative modulator of primary metabolism that inhibits cycloartenol synthase specifically, while showing no interaction with $\beta$-amyrin synthase. Amino acid substitution studies confirmed that, ketoconazole is specific modulator for cycloartenol synthase, LYS728 is the key amino acid for the interaction. Our present study is a novel approach for identifying a suitable specific positive modulator for the over production of desired triterpenoid secondary metabolites in the cell cultures of plants.
\end{abstract}

Keywords: Oxidosqualene cyclases, Cycloartenol synthase, $\beta$-amyrin synthase, Protein modeling, Docking studies

\section{Introduction}

Plant natural products and their derivatives play an important role in modern health care as frontline treatments for many diseases and as inspiration for chemical synthesized therapeutics (Pickens et al. 2011). Centella asiatica (L.) Urban, is a well-known medicinal plant, belongs to the family Apiaceae, has tremendous medicinal value and used as an important folk medicinal herb by natives of Asia, southern and middle Africa, southeastern United States and Australia, with a long history of therapeutic uses since

* Correspondence: veeke2012@gmail.com

Department of Biochemistry, Davangere University, Shivagangothri, Davangere, Karnataka 577002, India ancient times. Preparations of $C$. asiatica are used in traditional and alternative medicine due to the wide spectrum of pharmacological activities. In common with most traditional phyto-therapeutic agents, C. asiatica is claimed to possess a wide range of pharmacological effects, being used for strengthening the weakened veins (Allegra 1981), wound healing (Sugana et al. 1996), mental disorders (Appa rao et al. 1973), atherosclerosis, fungicidal, antibacterial (Oyedeji \& Afolayan 2005), sedative and anxiolytic (Kumar \& Gupta 2002), antioxidant and anticancer purposes (Jayashree et al. 2003; Babu et al. 1995), antidepressant (Chen et al. 2003), antiepileptic (Hausen 1993), antinociceptive and anti-inflammatory (Somchit et al. 2004) and radio protective (Sharma \& Sharma 2002). C. asiatica has also been reported to be a potent 


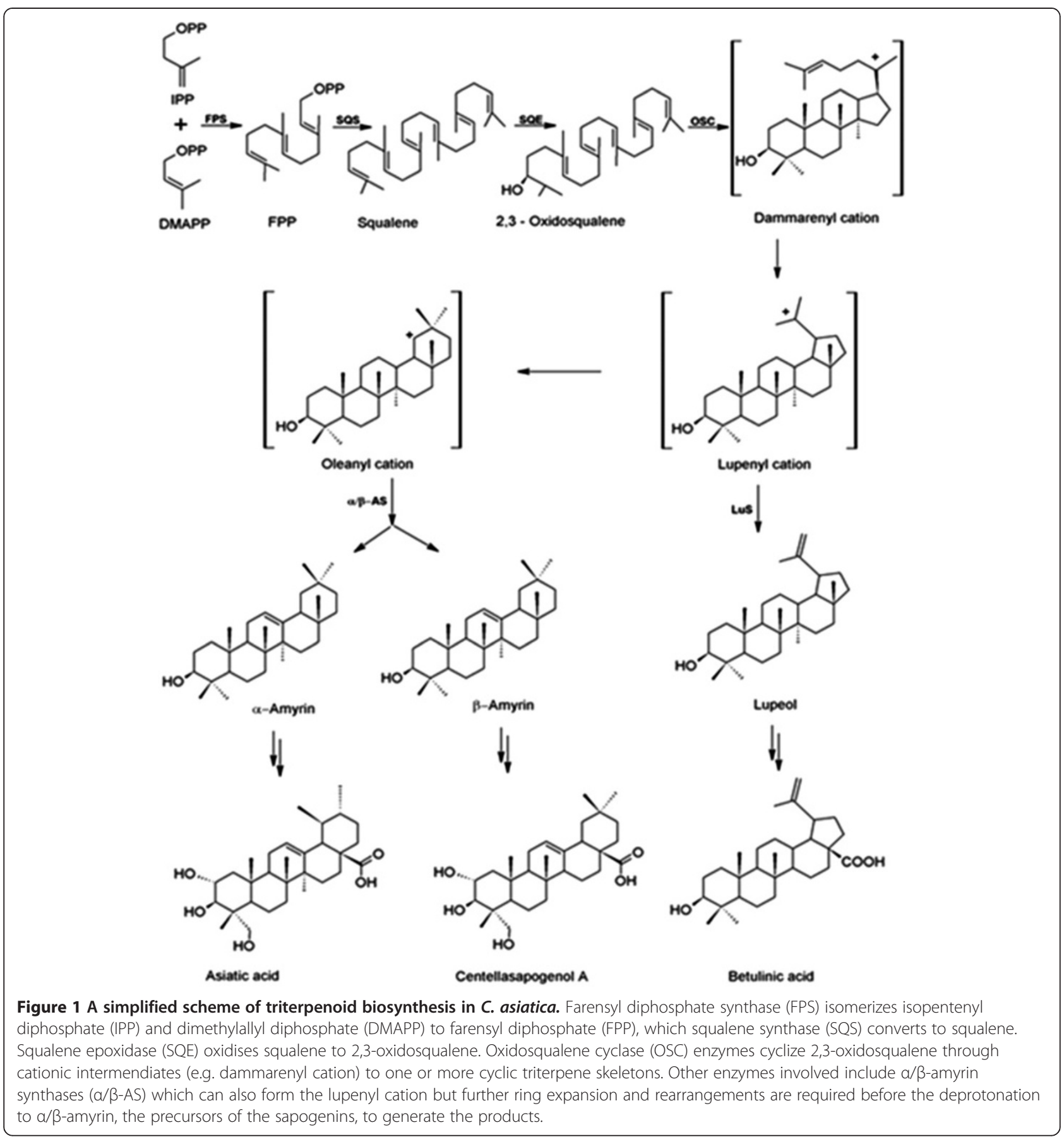

modulator of memory and hunger in both animals and humans, useful in the treatment of venous insufficiency, diarrhea, asthma, fever, improving cognition, tuberculosis and various skin lesions and aliments like leprosy, varicose ulcers, eczema, lupens, psoriasis, diarrhea and keloid (Gohil et al. 2010).

The immense medicinal properties of $c$. asiatica are attributed to the presence of secondary metabolites known as triterpenoid saponins. The plant contains large amount of triterpenoid saponins, collectively known as centelloids, includes asiaticoside, centelloside, madecassoside, brahmoside, brahminoside, thankuniside, sceffoleoside, centellose, asiatic-, brahmic-, centellic- and madecassic acids. The pharmacological and therapeutic applications of these triterpenes are mainly pentacyclic triterpenic acids and their respective glycosides, belonging to ursane- or oleanane-type, including asiatic acid, asiaticoside, madecassic acid, madecassoside, 
gi|41387168|gb|AAS01524.1| gi | 41387158 | gb|AAS 01523.1 |

gi|41387168|gb|AAS01524.1| gi | 41387158 | gb | AAS01523.1 |

gi|41387168|gb|AAS01524.1| gi | 41387158|gb|AAS01523.1|

gi|41387168|gb|AAS01524.1| gi | 41387158 | gb | AAS 01523.1 |

gi | 41387168|gb|AAS01524.1| gi | 41387158|gb|AAS01523.1|

gi | 41387168 | gb |AAS01524.1 | gi | 41387158|gb|AAS01523.1|

gi | 41387168|gb|AAS01524.1| gi|41387158|gb|AAS01523.1|

gi | 41387168|gb|AAS01524.1| gi 41387158 |gb|AAS01523.1|

gi | 41387168|gb|AAS01524.1| gi | 41387158 | gb | AAS 01523.1 |

gi | 41387168|gb|AAS01524.1| gi | 41387158 | gb | AAS 01523.1 |

gi | 41387168|gb|AAS01524.1| gi | 41387158 | gb | AAS01523.1 |

gi | 41387168 | gb | AAS 01524.1 | gi | 41387158 | gb | AAS 01523.1 |

gi | 41387168|gb|AAS01524.1| gi | 41387158|gb|AAS01523.1|

gi | 41387168|gb|AAS01524.1| gi | 41387158|gb|AAS01523.1|

gi | 41387168|gb|AAS01524.1| gi | 41387158 | gb | AAS01523.1 |

gi | 41387168|gb|AAS01524.1| gi | 41387158 | gb|AAS01523.1 |
MWKLKVAEGGNPWLRTVNNHVGRQIWEFDPKLGSPEELAEIEKARENFHN 50 MWKLKIAEGNGAYLYSTNNFVGRQIWEYDPDAGTPEERLEVEKLRETYKY 50 $* * * * *: * * * . .::^{*}:{ }^{* *} . * * * * * * *: * * . *: * * * \quad *: * * * * .::$

HRFEK--QHSSDLLMRLQFANEN-PRHEVLPQVKVKDIGDISEDKVTITL 97 NLINNGI HPCGDMLMRLQLIKESGLDLLSIPPVRLGEQEEVNYQVVTTAV 100

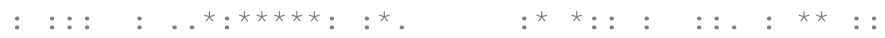

KRALSFYSTLQANDGHWAGDYGGPMFLMPGLVITLSITEALNAILSKEHK 147 KKALRLNRAIQAHDGHWPAENAGPMEFTPPLIIALYISGAIDTHLTIQHK 150

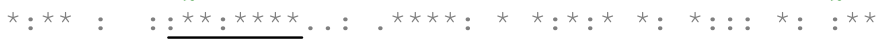

REICRYLYNHQNRDGGWGLHIEGPSTMFGSVLNYVTLRLLGEGTKDGQGA 197 KEMIRFIYLHQNKDGGWGFYIEGHSTMIGSALSYVALRLLGEGPDDGDGA 200 $: *: *:: * * * * \cdot * * * * *:: * * * * * *: * *, *, * *: * * * * * * * \ldots * *: * *$

MEKGRQWILDHGGATAITSWGRMWLSVLGVEEWSGNNPLPPEIWLFPYNL 247 VERARKWILDHGGAAS IPSWGKTYLAVLGVYEWEGCNPLPPEFWLFPEAL 250

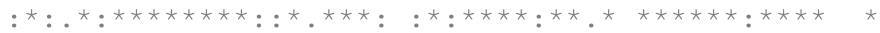

PFHPGRMWCHCRMVYLPMSYLYGKREVGPITPTVLSLRKELETVPYHEID 297 PYHPAKMWCYCRTTYMPMSYLYGKKYHGPITDLVISLRKEIHPIPYEKIN 300

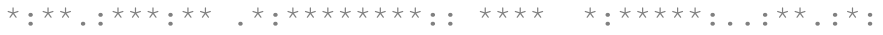

WNQARNLCAKEDLYYPHPLVQDILWAS IDKVLEPILMRWPGKKLREKALR 347 WNKQRHNCNKEDLYYPHSFIQDLLWDGLHYFTEPIIKMWP FNKLRKKGMK 350

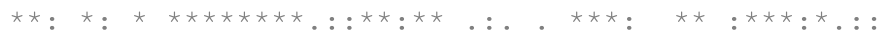

TVMEHIHYEDENTRYICIGPVNKVLNMLCCWAEDPNSEAFKLHLPRLYDF 397 RAIELMRYGGYESRFITIGCVSKSLDMMCWWAENPNGPEFKHHLARVPDY 400

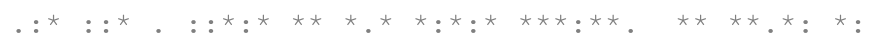

LWLAEDGMKMQGYNGSQLWDTAFAVQAIISTSLTEYCGPTLRKAHTFMKD 447 LWLAEDGMKMQSF-GSQLWDCVLATQAVMSTGMVDEYGDCLKKAHFYIKE 449

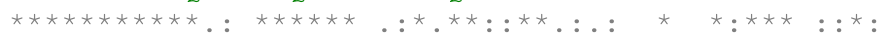

SQVLDDCPGDLDFWYRHISKGAWPFSTADHGWPISDCTAEGFKAVLLLSK 497 SQCKKNPSGDYASMCRYFTKGSWTFSDQDQGWVVSDCTAEALKCLLALSQ 499

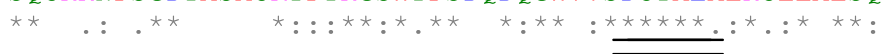

FPAELVGEPLDAKRLYDAVNVILSLQN-SDGGYATYELTRSYRWLELINP 546 MPEEIAGEKADVERLYDAVNVLLYLQSPISGGFAIWEPPVPRPYLQVLNP 549

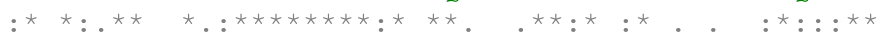

AETFGDIVIDYPYAECTSAAIQALSAFKKLYPGHRREEIQCSIEKAADFI 596 SEIFADIVVEKEHTECTASIIAALVAFKRLHPGHRSKEISVAIAKAVHFL 599

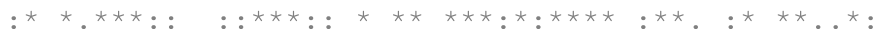

EKIQASDGSWYGSWGVCFTYGTWFGVKGLISAGRTFSNCSSIRKACYFLL 646 EGKQLEDGSWYGYWGICFLYGTFFALAGLASVGQTYENSETVRKAVKFFL 649

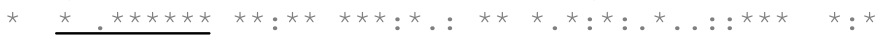

SKQLASGGWGESYLSCQNKVYTNLEGERSHVVNTGWAMLALIEAGQAERD 696 STQNEEGGWGESLESCPSEIFTPLEGNRTNLVQTSWAMLGLMFGGQATRD 699

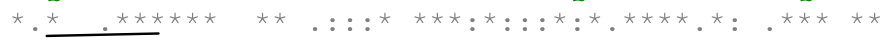

ATPLHHAAKLLINSQMENGDFPQEEIMGVFNKNCMITYAAYRNIFPIWAL 746 PTPLHRAAKLLINAQLNNGDFPQQETTGVYMKNCMLHYAEYRNVFPLWAL 749

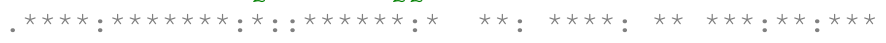

GDYRCRVLLAP 757

GEYRKRLWLSN 760

$*: * * *: *$ :

Figure 2 Alignment of amino acid residues of $C$. asiatica cycloartenol synthase and $\beta$-amyrin synthase. QW motifs are shown in single underline and DCTAE motifs in double underline. 
Table 1 Retrieved sequences from the databases

\begin{tabular}{|c|c|c|c|c|c|}
\hline \multirow[t]{2}{*}{ Source } & \multirow[t]{2}{*}{ OSC } & \multicolumn{2}{|c|}{ Accession no } & \multicolumn{2}{|c|}{ Sequence length } \\
\hline & & Nucleotide & Protein & Nucleotide & Protein \\
\hline $\begin{array}{l}\text { Centella } \\
\text { asiatica }\end{array}$ & $\begin{array}{l}\text { Cycloartenol } \\
\text { synthase }\end{array}$ & AY520819 & AAS01524 & $2547 \mathrm{bp}$ & 757 aа \\
\hline $\begin{array}{l}\text { Centella } \\
\text { asiatica }\end{array}$ & $\begin{array}{l}\beta \text {-amyrin } \\
\text { synthase }\end{array}$ & AY520818 & AASO1523 & $2562 \mathrm{bp}$ & 760 aа \\
\hline
\end{tabular}

Table 2 Results of protein modeling using SWISS-MODEL

\begin{tabular}{ccc}
\hline Template PDB ID & Target & Sequence identity \\
\hline 1W6JA & Cycloartenol synthase & $42.27 \%$ \\
1W6JA & $\beta$-amyrin synthase & $36.31 \%$ \\
\hline
\end{tabular}

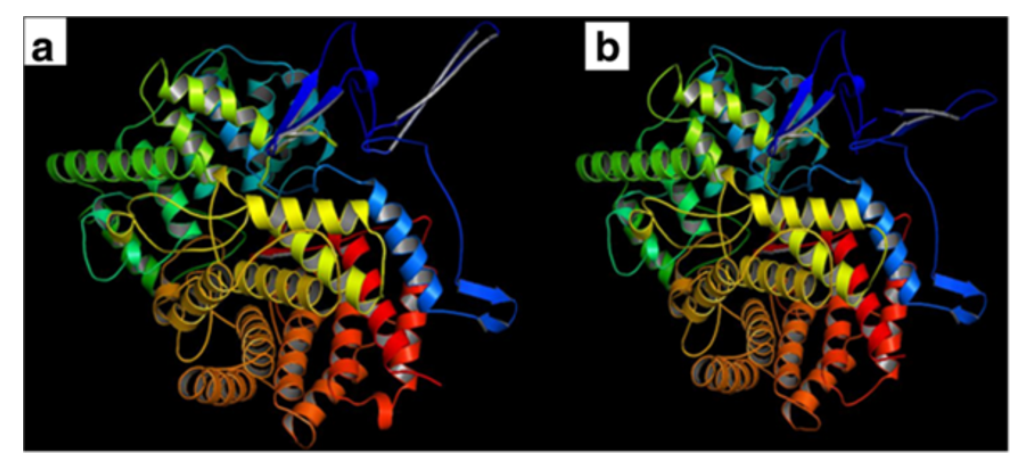

Figure 3 Modelled structures of two enzymes of $\boldsymbol{C}$. asiatica. a) Cycloartenol synthase and $\mathbf{b}$ ) $\beta$-amyrin synthase.

Table 3 Results of structure validation using RAMPAGE

\begin{tabular}{lcc}
\hline Assessment & Cycloartenol synthase & $\beta$-amyrin synthase \\
\hline Favored region & $92.90 \%$ & $90.09 \%$ \\
Allowed region & $4.50 \%$ & $5.30 \%$ \\
Outlier region & $2.50 \%$ & $3.70 \%$ \\
\hline
\end{tabular}
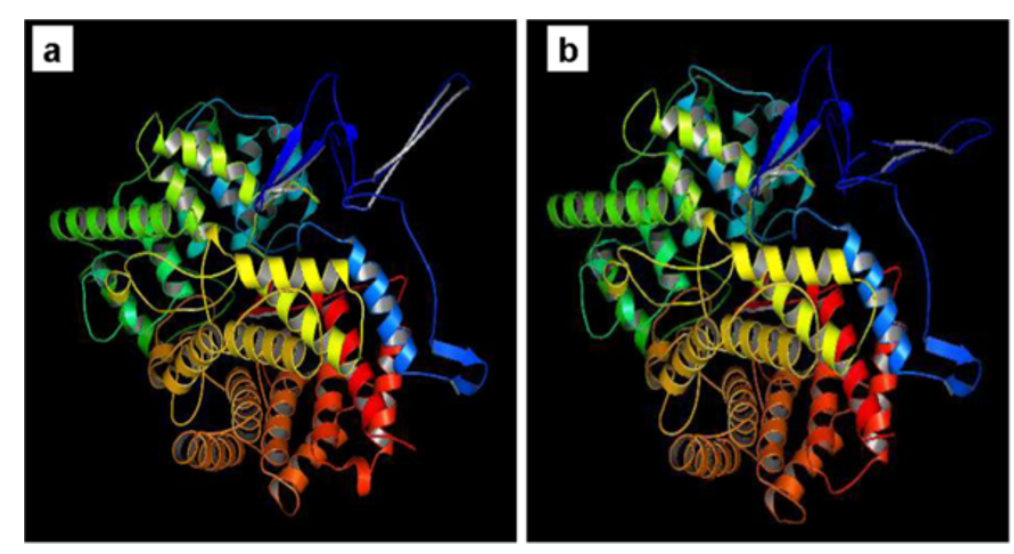

Figure 4 Modelled structures of reciprocally amino acid substituted enzymes of $C$. asiatica. a) Cycloartenol synthase and b) $\beta$-amyrin synthase. 
Table 4 Results of reciprocal studies of protein modeling using SWISS-MODEL

\begin{tabular}{cccc}
\hline $\begin{array}{c}\text { Template } \\
\text { PDB ID }\end{array}$ & Target & $\begin{array}{c}\text { Sequence } \\
\text { Identity }\end{array}$ & $\begin{array}{c}\text { QMEAN4 } \\
\text { Score }\end{array}$ \\
\hline 1W6JA & $\begin{array}{c}\text { Cycloartenol synthase with VAL } \\
728 \text { for LYS 728 }\end{array}$ & $42.14 \%$ & 0.424 \\
1W6JA & $\begin{array}{c}\text { 3-amyrin synthase with LYS } \\
\text { 728 for VAL 728 }\end{array}$ & $36.18 \%$ & 0.405 \\
& & & \\
\hline
\end{tabular}

Table 5 Results of reciprocal studies of structure validation using RAMPAGE

\begin{tabular}{lcc}
\hline Assessment & $\begin{array}{c}\text { Cycloartenol synthase } \\
\text { with VAL 728 } \\
\text { for LYS 728 }\end{array}$ & $\begin{array}{c}\text { B-amyrin synthase } \\
\text { with LYS 728 } \\
\text { for VAL 728 }\end{array}$ \\
\hline Favored region & $92.90 \%$ & $90.09 \%$ \\
Allowed region & $4.50 \%$ & $5.30 \%$ \\
Outlier region & $2.50 \%$ & $3.70 \%$ \\
$\begin{array}{l}\text { Structure Accuracy } \\
\text { with non-substituted }\end{array}$ & $99.9 \%$ & $99.9 \%$ \\
structures & & \\
\hline
\end{tabular}

brahmoside, brahmic acid, brahminoside, thankuniside, isothankuniside, centelloside, madasiatic acid, centic acid, cenellic acid, betulinic acid, indocentic acid etc.

In plants triterpenoids are synthesized via the isoprenoid pathway and derived from precursor 2,3-oxidosqualene, which is a common precursor molecule for both primary metabolites like plant sterols and secondary metabolites like triterpenoids (Phillips et al. 2006) (Figure 1). 2,3oxidosqualene, the common precursor is transformed into either sterols or triterpenoids by oxidosqualene cyclases
(OSCs) collectively known as triterpene synthases. Plants biosynthesize diverse triterpenoids and their genome encodes multiple OSC enzymes to form these skeletons. The level at which the structural diversity of triterpenes is generated depends on the cyclization of 2,3-oxidosqualene by different isoforms of OSCs such as cycloartenol synthase (CAS), lupeol synthase (LS) and $\alpha / \beta$-amyrin synthase (AS) (Mangas et al. 2006). Cyclization of 2,3-oxidosqualene through a protosteryl cation intermediate generates lanosterol and cycloartenol, the structural precursors to all the sterols in plants, while cyclization through a dammerenyl, baccharenyl and lupeonyl cation intermediates generates lupeol and $\alpha / \beta$-amyrin (Jenner et al. 2005) the precursors of the Centella pentacyclic triterpenoid saponins. The pertinent literature survey on sequence data of cycloartenol synthase (EC:5.4.99.8) (2,3-epoxysqualenecycloartenol cyclase), that catalyzes the cyclization of (S)2,3 -epoxysqualene to cycloartenol, and $\beta$-amyrin synthase (EC 5.4.99.39) (2,3-epoxysqualene- $\beta$-amyrin synthase), that catalyzes the cyclization of (S)-2,3-epoxysqualene to $\beta$-amyrin suggests that, the two enzymes isoforms and have several highly similar motiffs such as QW motif (Poralla et al. 1994) and DCTAE (Abe \& Prestwich 1994) motifs, even though the reaction products are different for each of these cyclases (Figure 2). In spite of the sequence similarity, structural and functional diversity of plant oxidosqualene cyclases, not even a single oxidosqualene structure from the plant per se has been reported in the literature till-date, although functional diversity has been reported, as multifunctional OSCs do exist.

Plant secondary metabolites are incorporated into a wide range of commercial and industrial applications, and fortuitously, in many cases, rigorously controlled plant in vitro cultures can generate valuable natural
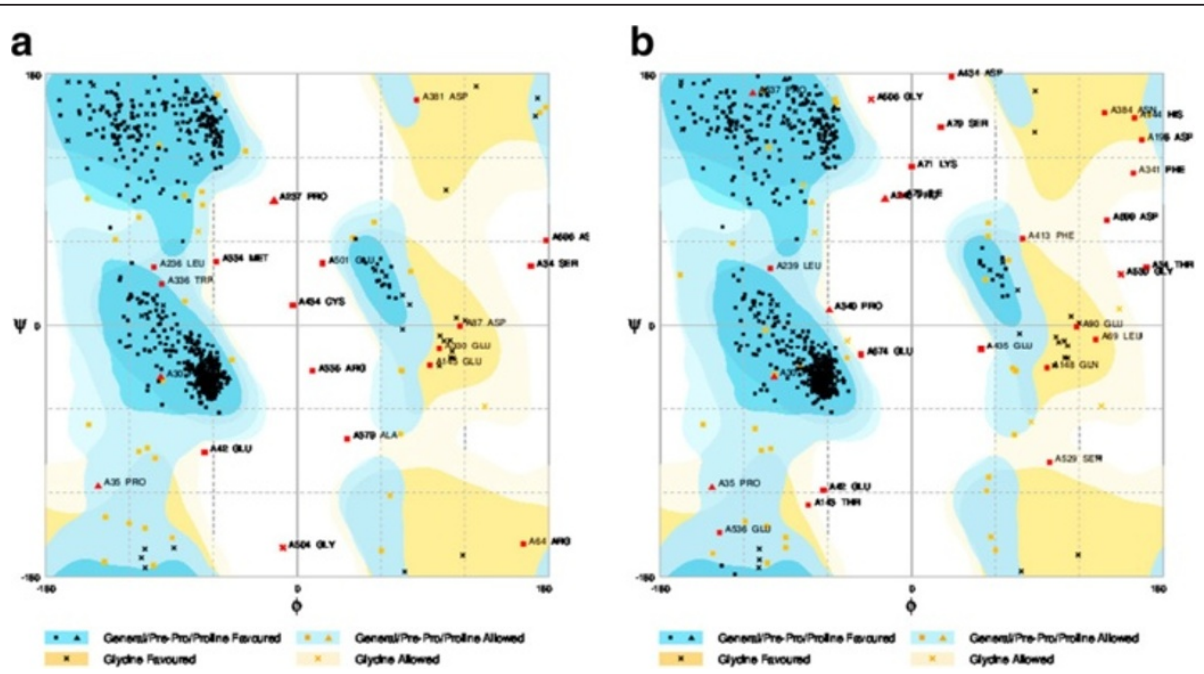

Figure 5 Ramachandran Maps of CAS and $\beta$-AS generated by Rampage. Dark blue and dark orange are favored regions. Light blue and light orange are allowed regions. a) Cycloartenol synthase and b) $\beta$-amyrin synthase. 

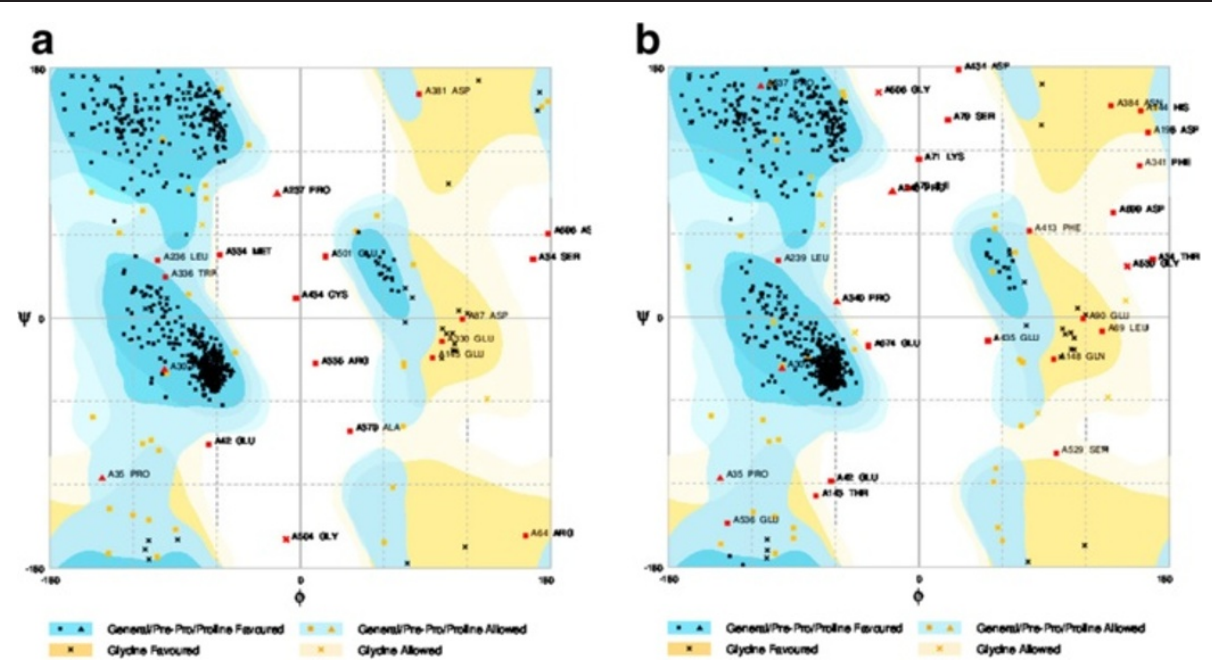

Figure 6 Ramachandran Maps of CAS and $\beta$-AS generated by Rampage for reciprocally amino acid substituted enzymes of $C$. asiatica. Dark blue and dark orange are favored regions. Light blue and light orange are allowed regions. a) Cycloartenol synthase and b) $\beta$-amyrin synthase.

products. There is great interest in developing alternatives to the intact plant for the production of secondary metabolites. The regular increasing demand in world marketplace for natural and renewable products has focused attention on in vitro plant materials as potential factories for phytochemical products, and has paved the way for new research exploring secondary product expression in vitro. In the recent years new approaches have been developed: the culturing of differentiated cells (e.g. shoots, roots), immobilized cell cultures, hairy root cultures induction by elicitors, tissue engineering and metabolic engineering (Anand 2010; Sevon et al. 1992; Sahai \& Knuth 1985; Zhao et al. 2005; Zupan et al. 2000).

One of the approaches by metabolic engineering for the over production of desired metabolite is by blocking the competitive pathways (Verpoorte et al. 1994). Thus, by blocking flow of 2,3-oxidosqualene towards primary metabolism, it is possible to channelize the substrate to secondary metabolism by using suitable modulators that can inhibit primary metabolites-sterol biosynthesis. The aim of the present study is to evaluate and suggest suitable modulators that function like inhibitors for sterol biosynthesis, while without affecting the biosynthesis of triterpenoid secondary metabolites of $C$. asiatica. To achieve this, in the present study we made an attempt to build the protein structures of cycloartenol synthase (CAS) an enzyme associated with plant sterol (primary metabolite) biosynthesis and $\beta$-amyrin synthase ( $\beta$-AS), an enzyme associated with plant triterpenoid saponin (secondary metabolite) biosynthesis, by homology modeling studies, and also to evaluate the specific interactions of these two enzymes with a panel of modulators by docking studies.
Table 6 Modulators for cycloartenol synthase and $\beta$-amyrin synthase

\begin{tabular}{|c|c|}
\hline SI. No. & $\begin{array}{l}\text { Modulators used in } \\
\text { the present study }\end{array}$ \\
\hline 1 & 2-aza-2,3-dihydrosqualene ${ }^{a}$ \\
\hline 2 & 3- $\beta$-(2-Diethylaminoethoxy) androsteroneandrosterone \\
\hline 3 & 4-hydroxypiperidine ${ }^{c}$ \\
\hline 4 & 8-azadecalin ${ }^{c}$ \\
\hline 5 & Benzenesulfonic acid ${ }^{d}$ \\
\hline 6 & Fluconazole ${ }^{e}$ \\
\hline 7 & Itraconazole $e^{e}$ \\
\hline 8 & Ketoconazole \\
\hline 9 & Methyl jasmonate ${ }^{f}$ \\
\hline 10 & NEM (N-ethylmaleimide) ${ }^{9}$ \\
\hline 11 & Sodium deoxycholate $^{\text {h }}$ \\
\hline 12 & $\begin{array}{l}\text { N-[(1,5,9)-Trimethyl-decayl]-4a, } \\
\text { 10-dimethyl-8-aza-trans-decal-3 } \beta \text {-ol' }\end{array}$ \\
\hline 13 & N-lauryl-N-dimethylamino-N-oxide ${ }^{j}$ \\
\hline 14 & Pectin/Oligogalacturonic acid ${ }^{k}$ \\
\hline
\end{tabular}

a Ref : (Delprino et al. 1983).

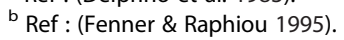

c Ref : (Taton et al. 1992).

${ }^{d}$ Ref : (Abe et al. 1993).

e Ref : (Goldman et al. 1996).

${ }^{f}$ Ref : (Kim et al. 2005).

${ }^{g}$ Ref : (Abe et al. 1992).

${ }^{\mathrm{h}}$ Ref : (Beastall et al. 1971).

'Ref : (Taton et al. 1986).

${ }^{j}$ Ref : (Schmitt et al. 1987).

${ }^{k}$ Ref : (Flores-Sanchez et al. 2002; Hu et al. 2003). 
<smiles>CC(C)=CCC/C=C(\C)CC/C=C(\C)CCCN(C)CC/C=C(/C)CCC1OC1(C)C</smiles><smiles>CCN(CC)CCOC1CCC2(C)C(=CC[C@H]3[C@@H]4CCC(=O)[C@@]4(C)CC[C@H]32)C1</smiles>

2-Aza-2,3-dihydrosqualene

3beta-(2-Diethylaminoethoxy)androstenone<smiles>OC1CCNCC1</smiles><smiles>C1CCC2NCCCC2C1</smiles><smiles>O=S(=O)(O)c1ccccc1</smiles><smiles>OC(Cn1cncn1)(Cn1cncn1)c1ccc(F)cc1F</smiles><smiles>C=c1ccc(=C)n1CC</smiles>

4-Hydroxypiperidine

8-Azadecalin

Benzenesulfonic acid

Fluconazole

NEM (N-ethylmaleimide)

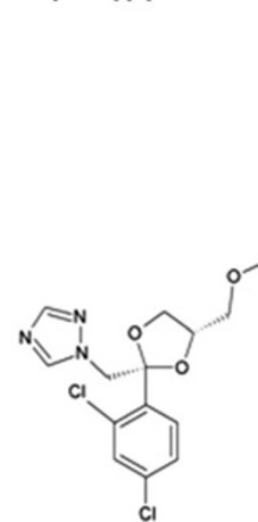

Itraconazole $\mathrm{H}_{3} \mathrm{C}$ $\mathrm{N}$-Lauryl-N-dimethylamino- $\mathrm{N}$-oxide<smiles>CC(C)CC(C)N1CC[C@@H]2[C@@](C)(O)CC[C@@]2(C)C1</smiles>

$\mathrm{N}$-[(1,5,9)-Trimethyl-decyl]-4alpha. 10-dimethyl-8-aza-trans-decal-3beta-ol

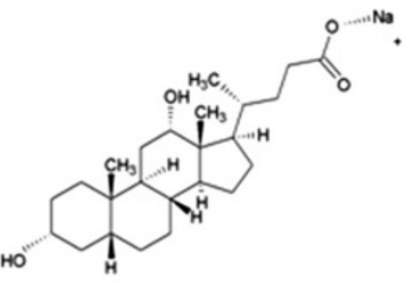

Sodium deoxycholate<smiles>O=C(O)[C@H]1O[C@@H](O)[C@H](O)[C@H](O)[C@@H]1O</smiles>

Oligogalacturinic acid

Figure 7 Structures of the modulators considered for the study.

\section{Computational methods}

Nucleotide sequences (cDNA) of cycloartenol synthase and $\beta$-amyrin synthase of Centella asiatica were retrieved from the NCBI database (http://www.ncbi.nlm.nih.gov/). These sequences were retrieved into FASTA format and used for further analysis. The modeling of the three dimensional structure of the protein was performed by using SWISS-MODEL (Arnold et al. 2006) (http:// swissmodel.expasy.org/), the built model was visualized in molecular visualization software. Structural validation of protein was done using RAMPAGE (Lovell et al. 2002) (http://mordred.bioc.cam.ac.uk/ rapper/rampage.php), phi-psi torsion angles for all the residues in structure were plotted in the Ramachandran Plot at RAMPAGE.
Information regarding modulators of cycloartenol synthase (EC 5.4.99.8) and $\beta$-amyrin synthase (EC 5.4.99.40) were retrieved from BRENDA (www.brenda-enzymes.org) and also through data mining. These modulators were considered as ligands for the docking studies. Structures of modulators (ligands) were retrieved from PubChem (http:// pubchem.ncbi.nlm.nih.gov/) and structures which are not available in the PubChem were drawn in ACD/ ChemSketch. All the sdf and mol files obtained from the PubChem and ACD/ChemSketch were converted into pdb files using the Open Babel software. Prediction of ligand binding sites in the modeled protein structure was performed using Q-SiteFinder server (Laurie \& Jackson 2005) (http://www.modelling.leeds.ac.uk/qsitefinder/), 
which were used in docking studies performed in Argus Lab. The modeled and docked structures were visualized in PyMol software.

In order to confirm the significance of LYS 728 in cycloartenol synthase and VAL 728 in $\beta$-amyrin synthase reciprocal studies were carried out by amino acid substitutions in the sequences of both cycloartenol synthase and $\beta$-amyrin synthase at position 728 residue, wherein cycloartenol synthase LYS 728 was substituted with VAL 728 and in $\beta$-amyrin synthase VAL 728 was substituted with LYS 728. Protein structures were modeled and ligand binding studies were carried out in SwissDock (www. swissdock.ch/), a free protein ligand docking web service powered by EADock DSS by the Molecular Modeling group of the Swiss Institute of Bioinformatics. The modeled and docked structures were visualized in PyMol software. Similarly modeling of the three dimensional structures both the proteins with substituted amino acid residues at position 728 were carried out using SWISS-MODEL (Arnold et al. 2006) (http://swissmodel.expasy.org/), the built model was visualized in molecular visualization software. Structural validation of protein was done using RAMPAGE (Lovell et al. 2002) (http://mordred.bioc.cam.ac.uk/ rapper/rampage.php), phi-psi torsion angles for all the residues in structure were plotted in the Ramachandran Plot at RAMPAGE.

\section{Results and discussion}

The retrieved sequences of cycloartenol synthase and $\beta$-amyrin synthase of Centella asiatica for the present study are listed in Table 1. Results of protein modeling showed the QMEAN4 score of 0.42 and 0.45 (estimated model reliability between $0-1$ ) taking human OSC (lanosterol synthase, PDB ID: $1 \mathrm{~W} 6 \mathrm{~J}$ chain A) as a template structure and the similarities of were scored as $42.27 \%$ and $36.31 \%$ (Table 2). The obtained structures were visualized in PyMol (Figure 3). The stereo chemical quality of the predicted models and accuracy of the protein model was evaluated by Ramachandran Map calculations computed with the RAMPAGE and the results showed that $92.9 \%$ residues of cycloartenol synthase and $90.09 \%$ residues of $\beta$-amyrin synthase are in favoured region (Table 3, Figure 4). Similar results were obtained when validations were carried out with amino acid substitution at 728 position in both the enzymes reciprocally, with $99.9 \%$ of accuracy to that of amino acid non-substituted protein structures (Tables 4, 5 and Figures 5, 6).

Ligands which are considered for the present study as modulators (inhibitors/activators) for both cycloartenol synthase and $\beta$-amyrin synthase are listed in the Table 6 and structures are shown in Figure 7. The ligands bind at a specific site on enzymes; the binding site residues and their numbers are listed in the Table 7. Docking studies with ligands revealed that, the energy values of ligands, 2-aza-2,
Table 7 Predicted ligand binding site of CAS and $\beta$-AS using Q-SiteFinder

\begin{tabular}{|c|c|c|c|}
\hline \multicolumn{2}{|c|}{ Cycloartenol synthase } & \multicolumn{2}{|c|}{$\beta$-amyrin synthase } \\
\hline Residues & Residue number & Residues & Residue number \\
\hline TYR & 118 & PRO & 124 \\
\hline PRO & 121 & PHE & 127 \\
\hline LEU & 124 & TRP & 258 \\
\hline TRP & 255 & CYS & 259 \\
\hline CYS & 256 & TYR & 260 \\
\hline HIS & 257 & ILE & 368 \\
\hline CYS & 258 & GLY & 369 \\
\hline ILE & 365 & CYS & 370 \\
\hline GLY & 366 & VAL & 771 \\
\hline PRO & 367 & GLN & 411 \\
\hline VAL & 368 & SER & 412 \\
\hline GLY & 409 & TRP & 418 \\
\hline TYR & 410 & PHE & 474 \\
\hline TRP & 479 & VAL & 483 \\
\hline ILE & 481 & ASP & 485 \\
\hline THR & 531 & CYS & 486 \\
\hline TYR & 532 & ILE & 534 \\
\hline GLU & 533 & TRP & 535 \\
\hline $\mathrm{PHE}$ & 550 & CYS & 565 \\
\hline ILE & 553 & TRP & 613 \\
\hline ASP & 556 & TYR & 619 \\
\hline TYR & 559 & *VAL & *728 \\
\hline SER & 609 & TYR & 729 \\
\hline TRP & 610 & LEU & 735 \\
\hline VAL & 725 & TYR & 737 \\
\hline PHE & 726 & TYR & 740 \\
\hline ASN & 727 & & \\
\hline${ }^{*}$ LYS & *728 & & \\
\hline CYS & 730 & & \\
\hline ILE & 732 & & \\
\hline
\end{tabular}

*Amino acid residue changes between two enzymes at ketoconazole binding site of cycloartenol synthase (LYS 728).

3-dihydrosqualene, 4-hydroxypiperidine, 8-azadecalin, benzenesulfonic acid, fluconazole, NEM (N-ethylmaleimide), $\mathrm{N}$-[(1,5,9)-trimethyl-decayl $]-4 \alpha, 10$-dimethyl-8-aza-transdecal-3 $\beta$-ol, N-lauryl-N-dimethylamino-N-oxide, methyl jasmonate, pectin/oligogalacturonic acid are non-specific and interact and inhibit both the enzymes (OSC isoforms) similarly. The modulators like 3 $\beta$-(2-diethylaminoethoxy) aldosterone and sodium deoxycholate did not show any interactions with cycloartenol synthase, whereas they showed affinity to bind $\beta$-amyrin synthase, hence these ligands could be considered as $\beta$-amyrin synthase specific modulators. 
Table 8 Docking results of CAS and BAS using Argus Lab

\begin{tabular}{|c|c|c|}
\hline \multirow[t]{2}{*}{ Ligands } & \multicolumn{2}{|c|}{$\begin{array}{l}\text { Best ligand pose } \\
(E=\mathrm{kcal} / \mathrm{mol})\end{array}$} \\
\hline & $\begin{array}{r}\text { Cycloartenol } \\
\text { synthase }\end{array}$ & $\begin{array}{l}\beta \text {-amyrin } \\
\text { synthase }\end{array}$ \\
\hline 2-Aza-2,3-dihydrosqualene & -19.1334 & -19.4249 \\
\hline $\begin{array}{l}\text { 3- } \beta \text {-(2-Diethylaminoethoxy) } \\
\text { androsteroneandrosterone }\end{array}$ & 一 $^{*}$ & -13.1427 \\
\hline 4-hydroxypiperidine & -6.96723 & -7.01001 \\
\hline 8-Azadecalin & -9.3033 & -10.027 \\
\hline Benzenesulfonic acid & -9.19979 & -10.1391 \\
\hline Fluconazole & -9.44939 & -10.1095 \\
\hline Itraconazole & 一 $^{*}$ & -* \\
\hline Ketoconazole & -8.82927 & -* \\
\hline NEM (N-ethylmaleimide) & -6.36966 & -6.89406 \\
\hline Sodium deoxycholate & 一 $^{*}$ & -14.3559 \\
\hline $\begin{array}{l}\text { N-[(1,5,9)-Trimethyl-decayl]-4alpha, 10- } \\
\text { dimethyl-8-aza-trans-decal-3beta-ol }\end{array}$ & -15.4413 & -15.4102 \\
\hline N-Lauryl-N-dimethylamino-N-oxide & -11.4094 & -12.2249 \\
\hline Pectin/Oligogalacturonic acid & -7.60546 & -7.48043 \\
\hline Methyl jasmonate & -11.2485 & -11.2796 \\
\hline
\end{tabular}

- ${ }^{*}$ No acceptable ligand poses were found.
While, itraconazole failed to interact with either of the enzymes.

Of all the modulators tested, ketoconazole has been evaluated as a negative modulator for primary metabolism of $C$. asiatica, as the molecule specifically inhibits cycloartenol synthase $(E=-8.82927 \mathrm{kcal} / \mathrm{mol})$, but failed to interact with $\beta$-amyrin synthase. Hence, this ligand ketoconazole could be considered as a specific inhibitor of cycloartenol synthase, and therefore could suppress or control primary metabolism i.e., sterol biosynthesis, and could channel the substrate 2,3-oxidosqualene for secondary metabolite (triterpenoid) biosynthesis, thus could enhance the secondary metabolism (Table 8). Ketoconazole interacts specifically with LYS 728 of cycloartenol synthase (Figure 8a). The interactions between the hydrogen atom in the LYS 728 and the oxygen atom in the ketoconazole were confirmed to be hydrophilic interactions (Figure 8a-d).

Reciprocal studies were carried out with amino acid substitutions at 728 position in the amino acid sequences of cycloartenol synthase LYS 728 was substituted with VAL 728 and $\beta$-amyrin synthase VAL 728 was substituted with LYS 728, protein models were docked with ketoconazole, using SwissDock software. Results of docking studies carried out with SwissDock using ketoconazole with normal and amino acid substituents of both cycloartenol synthase and $\beta$-amyrin synthase revealed that, ketoconazole could
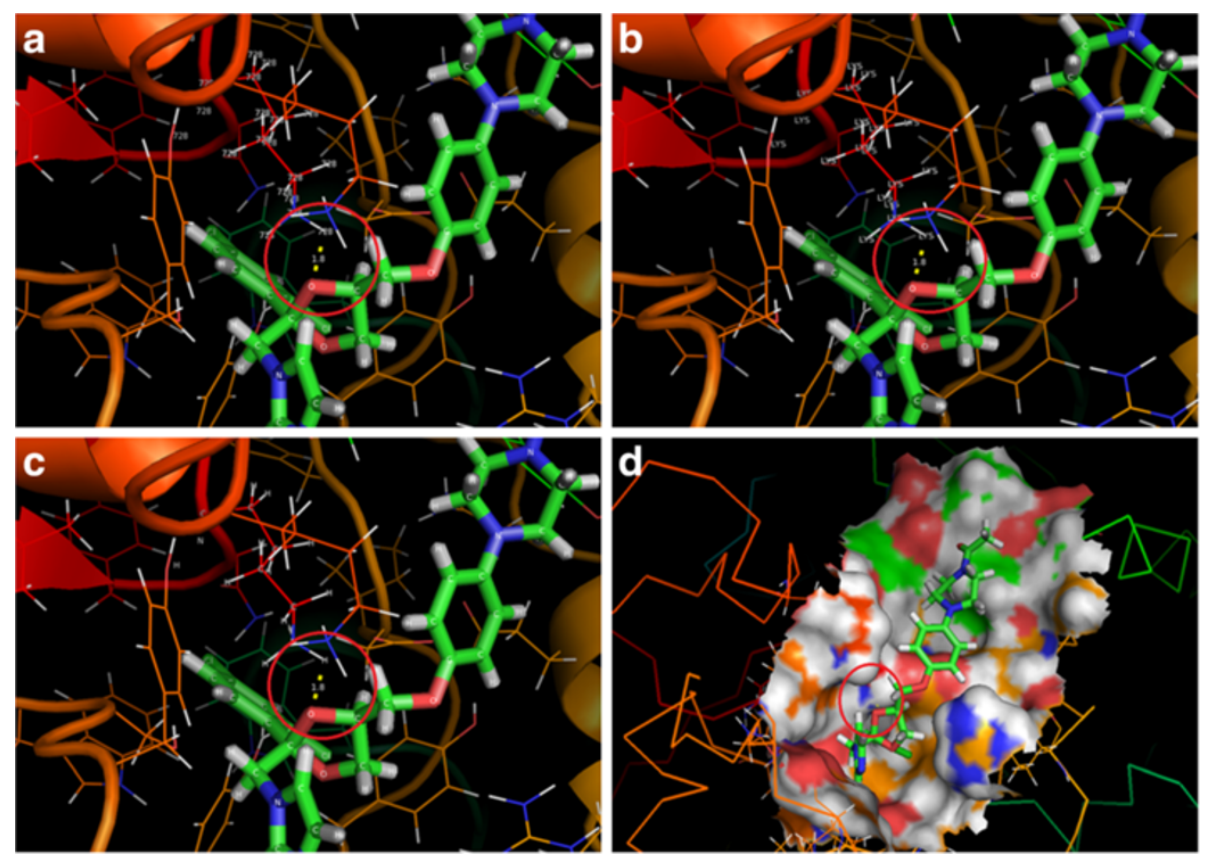

Figure 8 Interaction between CAS and ketoconazole in cartoon and solid representation. (a) Interaction between amino acid residue 728 and hydrogen atom of ketoconazole. (b) Interaction between amino residue LYS 728 of CAS and hydrogen atom of ketoconazole. (c) Interaction between hydrogen atom of CAS and oxygen atom of ketoconazole. (d) Binding surface of CAS. 
specifically interact with LYS 728 of normal cycloartenol synthase only and failed to interact with cycloartenol synthase containing VAL 728 for LYS 728, normal $\beta$-amyrin synthase and even with $\beta$-amyrin synthase containing LYS 728 for VAL 728 (Figure 9a-d). This confirms the specificity of ketoconazole interaction with cycloartenol synthase.

Ketoconazole is an azole fungicide, inhibits both fungal and mammalian cytochrome P450 oxidases (CYPs) that are associated with sterol metabolism. At concentrations $>100 \mathrm{nM}$, ketoconazole inhibits both fungal and mammalian CYP51s, that play an important role in ergosterol and cholesterol biosynthesis respectively, and also affect the activity of enzymes involved in catabolism of cholesterol. More specifically, ketoconazole inhibits 17hydroxylase-17,20-lyase (CYP17), the cholesterol side chain cleavage enzyme (CYP11A1), and the 11- $\beta$-hydroxylase (CYP11B1) (Vanden 1992). The 50\% inhibitory concentration $\left(\mathrm{IC}_{50}\right)$ of ketoconazole for lanosterol synthase was elucidated to be $11.7 \mathrm{nM}$ (Sakaeda et al. 2005). Of the two oxidosqualene cyclases investigated in the present study, cycloartenol synthase is considered to be a plant equivalent for cholesterol synthesis in animals and ergosterol

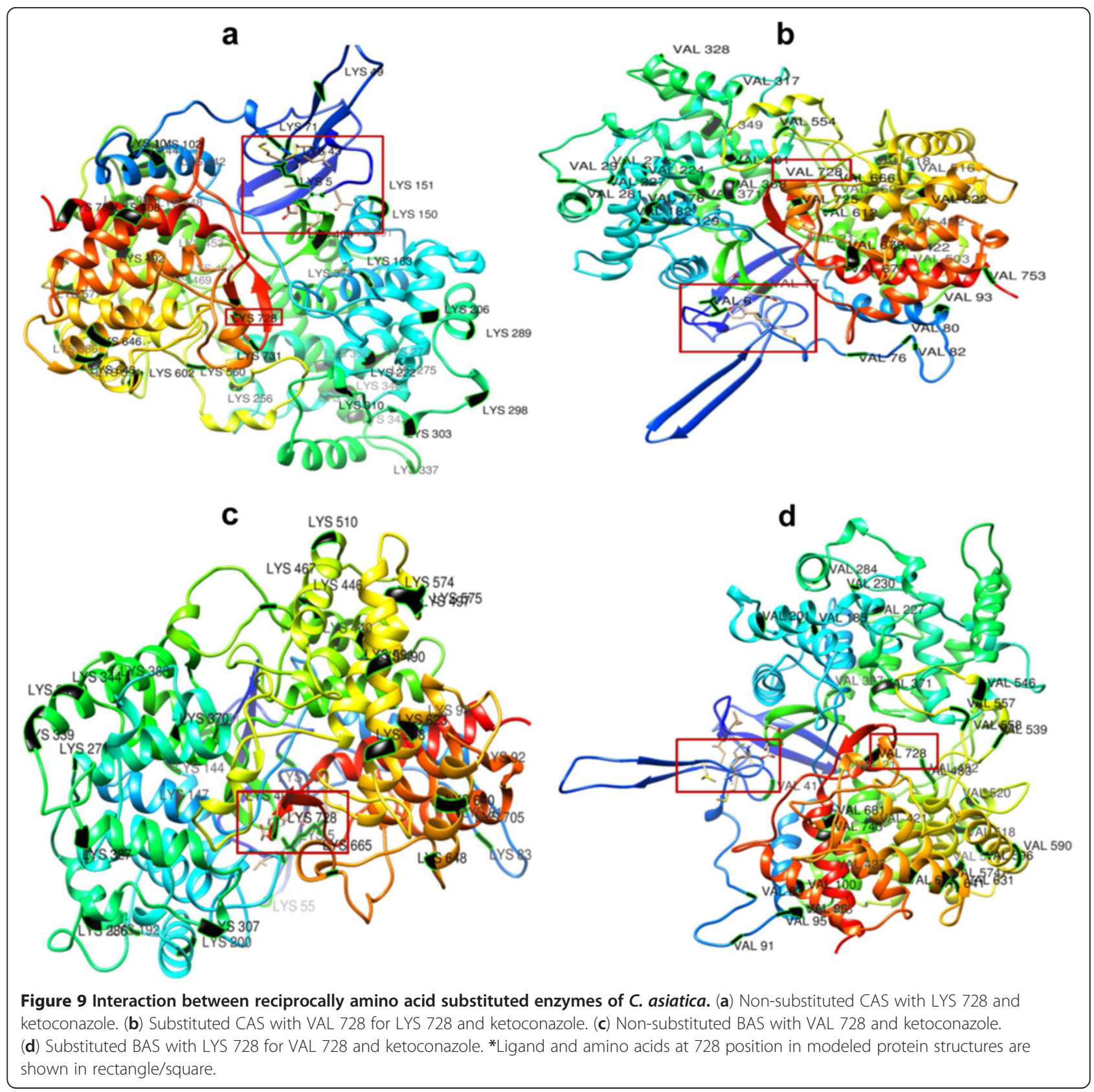


synthesis in fungi. The cyclization is executed with a remarkable degree of specificity and stereochemical control to produce protosterol intermediates. The two 'protosterols' that are subsequently modified to functional products such as cholesterol or phytosterols. The products are either lanosterol (in animals and fungi) or cycloartenol (in plants). The two enzymes mediate the cyclization process identically until the final deprotonation step. A deprotonation from C9 forms the 8,9-double bond of lanosterol whereas a deprotonation from $\mathrm{C} 19$ allows the cycloartenol cyclopropyl ring to close. Thus far, lanosterol synthase has been found only among the opisthokonts (animals + fungi + choanozoa), trypanosomatids (Trypanosoma, Leishmania) and dinoflagellates (Giner et al. 1991; Roger et al. 2006). All other eukaryotes that have been examined in this regard (at least members of the higher plants, green and red algae, amoebozoa, diatoms, euglenids and heterolobosea) make cycloartenol as their protosterol (Roger et al. 2006). Results of ligand binding site analysis using Q-SiteFinder revealed that, ketoconazole interaction with cycloartenol synthase is hydrophilic interaction with Lys 728 (hydrophilic amino acid) at the active site, whereas it is substituted with Val 728 (hydrophobic amino acid) at the same position in $\beta$-amyrin synthase. This hydrophilic-to- hydrophobic substitution of single amino acid residue at the enzyme active site probably distinguishes the two OSC isoforms to show distinctive interaction specificity with the ligand ketoconazole. This has also been proved through reciprocal amino acid substitution studies in both the enzymes.

\section{Conclusion}

The in vitro plant enzyme modulator studies are long and expensive one. It starts from target identification, after that, validates the targets and identifies modulators. Due to the limitation of throughput, accuracy and cost, experimental techniques cannot be applied widely; therefore, our study has shifted to in silico approaches such as homology modeling and proteinligand interactions. In silico approach has been of great importance as a versatile tool to develop fast and accurate target identification and prediction method for the discovery. The present work is an attempt to identify a specific modulator that would control the primary metabolism and over produce the secondary metabolites by channeling the precursor/ substrate in Centella asiatica cell cultures because of its immense medicinal importance. The docking studies particularly with ketoconazole has explored the fact that, the two oxidosqualene isoforms differ from each other by virtue of a single amino acid substitution at 728 position from lysine to valine. The results of the present study, suggest that, because of its hydrophilic interaction, ketoconazole can possibly channelize the precursor molecule 2,3-oxidosqualene towards secondary metabolism by functioning like a negative modulator of sterol biosynthesis, and at the same time as a positive modulator for the over production of triterpenoid secondary metabolites in not only cell cultures Centella asiatica of other plants too. To prove this, in our lab we have initiated studies using the cell suspension cultures of Gymnema sylvestre, for the overproduction of gymnemic acid, a group of triterpenoid saponins.

\section{Competing interests}

The authors declare that they have no competing interests.

\section{Authors' contributions}

VK, CSK and GH have carried out the molecular docking studies, i.e., participated in the sequence alignment and docking studies and validation of models. DVP, NKV and GB have retrieved the ligands information and drafted the manuscript. All authors read and approved the final manuscript.

\section{Acknowledgement}

The Financial support from Department of Biotechnology, Ministry of Science and Technology, Government of India (No. BT/PR13872/PID/06/585/2010; Dt.: 30-09-2011) in the form Research Project grant to Vadlapudi Kumar is gratefully acknowledged.

Received: 27 November 2012 Accepted: 19 April 2013 Published: 27 April 2013

\section{References}

Abe I, Prestwich GD (1994) Active site mapping of affinity labeled rat oxidosqualene cyclase. J Biol Chem 269(2):802-804

Abe I, Sankawa U, Ebizuka Y (1992) Purification of squalene-2,3-epoxide cyclase from pea seedlings. Chem Pharm Bull 40(7):1755-1760

Abe I, Rohmer M, Prestwich GD (1993) Enzymatic cyclization of squalene and oxidosqualene to sterols and triterpenes. Chem Rev 93:2189-2206

Allegra C (1981) Comparative Capillaroscopic study of certain bioflavonoids and total triterpenic fractions of Centella asiatica in venous insufficiency. Clin Ther 99:507-513

Anand S (2010) Various approaches for secondary metabolite production through plant tissue culture. Pharmacia 1(1):1-7

Appa rao MVR, Srinivasan K, Rao K et al (1973) The effect of mandookparni (Centella asiatica) on the general mental ability (Medhya) of mentally retarded children. J Res Indian Med 8:9-16

Arnold K, Bordoli L, Kopp J, Schwede T (2006) The SWISS_MODEL workspace: a web-based environment for protein structure homology modeling. Bioinformatics 22(2):195-201

Babu TD, Kuttan G, Padikkala J (1995) Cytotoxic and anti-tumor properties of certain texa of umbelliferae with specific reference to Centella asiatica (L) Urban. J Ethnopharmacol 48(1):53-57

Beastall GH, Rees HH, Goodwin TW (1971) Properties of 2,3-oxidosqualene cycloartenol cyclase from Ochromonas malhamensis. FEBS Lett 18(1):175-178

Chen Y, Han T, Qin L, Rui Y, Zheng H (2003) Effects of total triterpenes of Centella asiatica on the depression behavior and concentration of amino acid in forced swimming mice. Zhong Yao Cai 26(12):870-873

Delprino L, Balliano G, Cattel L, Benveniste P, Bouvier P (1983) Inhibition of higher plant 2,3-oxidosqualene cyclases by 2-aza-2,3-dihydrosqualene and its derivatives. J Chem Soc Chem Commun 7:381-382

Fenner GP, Raphiou I (1995) Growth of Cucurbita maxima L. plants in the presence of the cycloartenol synthase inhibitors U18666A. Lipids 30(3):253-256

Flores-Sanchez IJ, Ortega-Lopez J, Montes-Horcasitas MC, Ramos-Valdivia AC (2002) Biosynthesis of sterols and triterpenes in cell suspension culture of Uncaria tomentosa. Plant Cell Physiol 43(12):1502-1509

Giner JL, Wünsche L, Andersen RA, Djerassi C (1991) Dinoflagellates cyclize squalene oxide to lanosterol. Biochem Syst Ecol 19:142-145

Gohil KJ, Patel JA, Gajjar AK (2010) Pharmacological review on Centella asiatica: a potential herbal cure-all. Indian J Pharm Sci 72(5):546-556

Goldman RC, Zakula D, Capobianco JO, Sharpe BA, Griffin JH (1996) Inhibition of 2,3-oxidosqualen-lanosterol cyclases in Candida albicans by Pyridinium Ionbased inhibitors. Antimicrob Agents Chemother 40(4):1044-1047 
Hausen BM (1993) Centella asiatica (Indian pennywort), an effective therapeutic but a weak sensitizer. Contact Dermatitis 29(4):175-179

Hu X, Neill SJ, Cai W, Tang Z (2003) Nitric oxide mediates elicitor-induced saponin synthesis in cell cultures Panax ginseng. Funct Plant Biol 30:901-907

Jayashree G, Kurup MG, Sudarslal VS et al (2003) Antioxidant activity of Centella asiatica on lymphoma bearing mice. Fitoterpia 74(5):431-434

Jenner H, Townsend B, Osbourn A (2005) Unravelling triterpene glycoside synthesis in plants: phytochemistry and functional genomics join forces Planta 220(4):503-506

Kim OT, Kim MY, Hwang SJ, Ahn JC, Hwang B (2005) Cloning and molecular analysis of cDNA encoding cycloartenol synthase from Centella asiatica (L.) Urban. Biotechnol Bioprocess Eng 10:16-22

Kumar MHV, Gupta YK (2002) Effect of different extracts of Centella asiatica on cognition and markers of oxidative stress in rats. J Ethnopharmacol 79(2):253-260

Laurie AT, Jackson RM (2005) Q-SiteFinder: an energy-based method for the prediction of protein-ligand binding sites. Bioinformatics 21(9):1908-1916

Lovell SC, Davis IW, Arendall WB III, de Bakker PIW, Word JM, Prisant MG, Richardson JS, Richardson DC (2002) Structure validation by Calpha geometry: phi, psi and $C \beta$ deviation. Proteins 50(3):437-450

Mangas S, Bonifill M, Osuna L, Moyano E, Tortoriello J, Cusido RM, Pinol MT, Palazom J (2006) The effect of methyl jasmonate on triterpene and sterol metabolism of Centella asiatic, Ruscus aculeatus, and Galphimia glauca cultured plants. Phytochemistry 67(18):2041-2049

Oyedeji OA, Afolayan AJ (2005) Chemical composition and antibacterial activity of the essential oil of Centella asiatica growing in South Africa. Pharma Biol 43(3):249-252

Phillips DR, Rasbery JM, Bartel B, Matsuda SPT (2006) Biosynthetic diversity in plant triterpene cyclization. Curr Opin Plant Biol 9(3):305-314

Pickens LB, Tang Y, Chooi Y (2011) Metabolic engineering for the production of natural products. Ann Rev Chem Biomol Engg 2:211-236

Poralla K, Hewelt A, Prestwich GD, Abe I, Reipen I, Sprenger G (1994) A specific amino acid repeat in squalene and oxidosqualene cyclases. Trends Biochem Sci 19(4):157-158

Roger ES, Alexander SB, Linda LJ, Jacob RW (2006) Steroids, triterpenoids and molecular oxygen. Philos Trans R Soc Lond B Biol Sci 361 (1470):951-968

Sahai O, Knuth M (1985) Commercializing Plant Tissue Culture. Processes: Economics, Problems and Prospects. Biotechnol Prog 1(1):1-9

Sakaeda T, Iwaki K, Kakumoto M, Nishikawa M, Niwa T, Jin JS, Nakamura T, Nishiguchi K, Okamura N, Okumura K (2005) Effect of micafungin on cytochrome P450 3A4 and multidrug resistance protein 1 activitities, and its comparison with azole antifungal drugs. J Pharm Pharmacol 57:759-764

Schmitt P, Gonzales R, Benveniste P, Cerutti M, Cattel L (1987) Inhibition of sterol biosynthesis and accumulation of 2,3-oxidosqualene in bramble cell suspension culture treated with 2-aza-2,3-dihydrosqualene and 2-aza2,3-dihydrosqualene-N-oxide. Phytochemistry 26:2709-2714

Sevon N, Hiltunen R, Oksman-Caldentey KM (1992) Chitosan increases hyoscyamus content in hairy root cultures of Hyoscyamus muticus. Pharm Pharmacol Lett 2:96-99

Sharma J, Sharma R (2002) Radioprotection of Swiss albino mouse by Centella asiatica extract. Phytother Res 16(8):785-786

Somchit MN, Sulaiman MR, Zuraini A, Samsuddin LN, Somchit N, Israf DA et al (2004) Antinociceptive and antiinflammatory effects of Centella asiatica. Indian J Pharmacol 36(6):377-380

Sugana L, Sivakumar P, Chandrakasan G (1996) Effects of Centella asiatica extract on dermal wound healing in rats. Indian J Exp Biol 34(12):1208-1211

Taton M, Benveniste P, Rahier A (1986) N-[(1,5,9)-Trimethyl-decyl]-4alpha,10dimethyl-8-aza-trans-decal-3beta-ol a novel potent inhibitor of 2,3oxidosqualene cycloartenol and lanosterol cyclases. Biochem Biophys Res Commun 138(2):764-770

Taton M, Benveniste P, Rahier A, Johnson WS, Liu H, Sudhakar AR (1992) Inhibition of 2,3-oxidosqualene cyclases. Biochemistry 31(34):7892-7898

Vanden BH (1992) Inhibitors of P450-dependend steroid biosynthesis: from research to medical treatment. J Steroid Biochem 43:1003-1021
Verpoorte R, van der Heijden R, Hoge JHC, ten Hoopen HJG (1994) Plant cell biotechnology for the production of secondary metabolites. Pure Appl Chem 66(10/11):2307-2310

Zhao J, Davis LC, Verpoorte R (2005) Elicitor signal transduction leading to production of plant secondary metabolites. Biotechnol Adv 23(4):283-333

Zupan J, Muth TR, Draper O, Zambryski P (2000) The transfer of DNA from Agrobacterium tumefaciens into plants: a feast of fundamental insights. Plant J 23(1):11-28

doi:10.1186/2193-1801-2-189

Cite this article as: Kumar et al:: Homology modeling and docking studies on oxidosqualene cyclases associated with primary and secondary metabolism of Centella asiatica. SpringerPlus 2013 2:189.

\section{Submit your manuscript to a SpringerOpen ${ }^{\circ}$ journal and benefit from:}

- Convenient online submission

- Rigorous peer review

- Immediate publication on acceptance

- Open access: articles freely available online

- High visibility within the field

- Retaining the copyright to your article

Submit your next manuscript at $>$ springeropen.com 